\title{
Patriotismo constitucional: sobre el significado de la lealtad política republicana *
}

\author{
JOSÉ MARÍA ROSALES \\ Universidad de Málaga
}

Trato de precisar en este trabajo el significado de la idea de patriotismo constitucional (Verfassungspatriotismus), introducida en 1979 por el polítólogo Dolf Sternberger y divulgada con éxito más recientemente por Jürgen Habermas. La reflexión de Sternberger surge como felicitación por el papel que la Constitución alemana de 1949 ha jugado en la consolidación del sistema político. Pero sobre todo pone de relieve la capacidad que el texto constitucional ha demostrado para inspirar una cultura política democrática y proveer a la sociedad, escindida y traumatizada por la barbaric del nazismo, la tarea de construir una nueva identidad colectiva. Para entrar en materia conviene, sin embargo, hacer una aclaración previa.

En primer lugar, que el significado de la idea de patriotismo constitucional pertenece a la tradición republicana desde sus orígenes en Roma. El modelo político republicano se construye como un equilibrio entre derecho y libertad. La constitución misma y el sistema de instituciones se articulan sobre ese equilibrio fundamental, que genera un tipo de adhesión cívica basada en el reconocimiento del «amor a la patrian, es decir, al derecho y al sistema de instituciones del país. Los antecedentes pueden documentarse en los textos de Tito Livio o Cicerón, hasta los de Maquiavelo y los humanistas del Renacimiento, Montesquieu o Rousseau y, por supuesto, en los textos de Saint-Pierre o Kant sobre la paz en Europa y la paz mundial, que defienden un republicanismo de alcance universalista, asumido ya en el siglo xx por autores como Arendt o Dahrendorf: la tradición en la que se inserta justamente la obra de Sternberger.

En segundo lugar, que el interés de Habermas por este problema no ha sido improvisado, sino que se remonta cuando menos a su trabajo de 1974 «Können komplexe Gesellschaften eine vernünftige Identität ausbilden?» y comprende asimismo hasta sus últimas publicaciones, donde llega a plantear una analogía entre el papel que ha jugado el patriotismo constitucional en la formación de una nueva cultura política en Alemania y el papel que podría jugar un patriotismo constitucional trasladado al entorno de la Unión Europea en la formación y en la consolidación de la cultura política comunitaria. De ahí que

* Recoge este artículo, de forma abreviada y con modificaciones, la argumentación de los capítulos $I$ al $\mathrm{V}$ de mi trabajo Patriotismo, nacionalismo y ciudadania: en defensa de un cosmopolitismo crivico, Bogotá, Universidad Externado de Colombia, 1997, pp. 31-133. 
el breve repaso de su trayectoria teórica tenga sólo el objetivo de apuntar el contraste y la continuidad con el trabajo de Sternberger.

\section{Habermas über alles}

Comencemos por reparar en el cariz que adopta la referencia de Habemas a la obra de Sternberger. Insuficiente cuando menos por tratarse de una referencia sólo nominal que se diluye hasta desapa recer justo cuando la proximidad de sus posturas se hace más patente. En la conferencia pronunciada en 1987 con motivo de la concesión del premio Sonning en Dinamarca, «Geschichtsbewußtsein und posttraditionelle Identität», Habermas reconoce cómo, a propósito de la experiencia alemana de posguerra que ha permitido cuestionar la relación natural entre identidad cultural y modelo de Estado, «en la República Federal Dolf Sternberger ha observado un cierto patriotismo constitucional: una disposición a identificarse con el ordenamiento político y con los principios de la Constitución» ${ }^{5}$. No hace, sin embargo, mención a ninguno de sus trabajos, aunque su argumentación coincide sustancialmente con la de este autor.

Así, por cjemplo, cuando a continuación señala que el aprendizaje de la democracia ha generado una nueva forma de patriotismo «cristalizado en torno a los principios del Estado democrätico constitucional» y que esta nueva identidad, de carảcter universalista, resulta incompatible con cualquier otra forma de identidad que no reconozca «la profunda ambivalencia de toda tradición». El nacionalismo alemán se había caracterizado por blindar su narración del pasado frente a la crítica y fue esto lo que puso en cuestión su pretensión de imparcialidad y lo que debilitó la racionalidad de su reconstrucción histórica. Sin embargo, como Habermas reconoce, la formación de una identidad política post- nacional no acaba por sustituir a las identidades nacionales. A pesar de su inconmensurabilidad, tienen que convivir, dado que la historia se interpreta desde ambas perspectivas.

Ambos extremos delimitan asimismo el «debate de los historiadores», que desde 1986 convoca a las diferentes interpretaciones que reconstruyen la memoria histórica de la República Federal. Por supuesto que los antecedentes resultan indispensables para entender el curso de la discusión. Y éstos pueden situarse, entre otras referencias, en la elaboración misma del diseño de la Ley Fundamental de 1949. Su carácter de provisionalidad, a la espera de una reunificación entre las dos Alemanias, no cerraba, sino que, al contrario, proveía un marco político integrador para abordar la tarea insustituible de una reconciliación con el pasado. En esta línea se situaban Ios trabajos constitucionales de Sternberger, cuyas ideas entraron a formar parte del debate.

A finales de 1988 aparece publicada en la revista francesa Globe una entrevista de Habermas con Jean-Marc Ferry. El problema del historicismo en el análisis del Holocausto es ahora el argumento para diagnosticar el estado de la cuestión en el debate de los historiadores. Habermas defiende que su historización, necesaria sin duda, no basta como método de trabajo. Una comprensión contextualizada, desde el punto de vista de los agentes del genocidio, resulta racionalmente intolerable (se suma aquí a la demanda de reescritura de la historia por Walter Benjamin en sus Geschichtsphilosophische Thesen). Stemberger, a quien Habermas cita, lo habia precisado: «Auschwitz no puede en absoluto comprenderse; Ante todo, porque rompe el límite de Ia dignidad humana y de toda razonabilidad al convertir el genocidio en un acto normal, perpetrado como política pública, es decir, organizado desde el aparato del Estado, en la que estuvo implicado «indirectamente todo un pueblo», como 
Habermas reconoce. «Desde entonces», continúa, "ya no es posible ninguna vida consciente sin desconfiar de las continuidades que pretenden mantenerse fuera de toda duda y obtener su validez también de su propia incuestionabilidad $*$.

La segunda parte de la entrevista gira en torno a la tensión entre la identidad colectiva de carácter nacionalista, entendida como adhesión a una conciencia histórica difícilmente problematizada, y la identidad de tipo postnacional, fundada en los principios universalistas del constitucionalismo moderno. Para Habermas, el nacionalismo, que en Alemania degenera en «darwinismo social» y culmina en unà «locura racial», ha quedado deslcgitimado como fundamento de toda identidad política racional. Su alternativa pasa por una reapropiación crítica del pasado que haga posible asumir la discontinuidad neccsaria: sólo la «superación del fascismo crea la perspectiva especifica desde la que se entiende una identidad postnacional, formada en torno a los principios universalistas del Estado de derecho y de la democracia»?

Se trata, en efecto, de la alternativa representada por la idea de patriotismo constitucional, que el propio entrevistador atribuye sin más a Habermas. Para entonces ha desaparecido toda alusión a Sternberger. La omisión se detecta también, por ejemplo, en un trabajo de 1990 , «Nochmals: Zur Identität der Deutschens ${ }^{8}$, donde al comentar la idea de patriotismo constitucional Habermas remite a su conferencia de 1987. $\mathrm{Y}$ en otro texto del mismo año, «Staatsbürgerschaft und nationale Identität», donde establece el paralelismo entre el caso alemán y la ciudadanía de la Unión Europea, por entonces aün formulada sólo como documento de trabajo. Este texto ha conocido una amplísima difusión internacional gracias a las casi simultáneas traducciones a otras lenguas. Posteriormente se incluyó como apéndice ter- cero de los «Estudios preparatorios y complementos» de su Faktizität und Geltung?

Por último, y deteniendo ya en este punto este repaso anecdótico de omisiones, durante una conferencia pronunciada en la Universidad de Bolonia en junio de 1995, «The European nation state - its achievements and its limits. On the past and future of sovereignty and citizenship» ${ }^{10}$, donde vuelve a hablar de la «autocomprensión "postnacional" del Estado constitucionaly, hecha posible desde la perspectiva de una ciudadanía democrática universalista, que viene a configurarse como alternativa de la ciudadanía nacional. El propio Habermas reconoce que la tensión entre ambos modelos es ya una condición constitutiva de la política alemana y también, aunque en diferente medida, de la política europea. La tensión contribuye, además, a operar una lenta pero irreversible transformación del modelo de Estado nacional, aunque el sentido de esa transformación en curso se vislumbra de momento sólo en los términos de un análisis de prospectiva. A esas alturas, Ia tesis de Habermas ha evolucionado notablemente sobre la de Sternberger, fallecido en julio de 1989, pero mantiene, sin embargo, lo esencial de su argumentación. Corresponde ahora tras este primer apartado presentar a grandes rasgos la interpretación de Sternberger.

\section{Nacionalismo, patriotismo y constitución}

Patriotismo y constitución no forman un binomio que se explique a sí mismo. Configuran, en cambio, una relación que, a pesar de su componente emotivo, no puede entenderse sino como resultado de una adhesión política libremente razonada. $\mathrm{La}$ lealtad patriótica se funda en la libertad que la patria hace posible y que la Constitución reconoce y garantiza. Sternberger cita reiteradamente la certera frase de La 
Bruyère: «Il n'y a pas de patrie dans le despotismew. No obstante, cabe también hablar de un patriotismo no razonado, sino inducido a través de inculturación o de adoctrinamiento. En ese caso, sin embargo, ausente el elemento racional, la diferencia con la idea de nacionalismo se atenúa. Veamos por qué.

Entre patriotismo y nacionalismo, términos que habitualmente se suelen considerar sinónimos, pueden destacarse algunas notas distintivas básicas. Una primera viene determinada por el papel que la dccisión racional y libre del ciudadano juega en la configuración de la lealtad colectiva: preconvencional (es decir, inducida) oconvencional (aún no universalista), adaptando la terminología moral de Kohlberg, en el caso del nacionalismo, y postconvencional en el caso del patriotismo. Una segunda diferencia nos remite ya a la objetivación propia de cada tipo de lealtad. De acuerdo con la precisa formulación de Walker Connor, el patriotismo representa «una adhesión emocional al propio Estado o país y a sus instituciones políticas», micntras que el nacionalismo lo es «al propio pueblow, es decir, "al propio grupo etnonacional» ". Sólo en un reducido número de casos donde el Estado y la nación son indistinguibles, como Japón o Alemania (este último con ciertas reservas, como veremos), puede hablarse de una misma lealtad patriótico-nacional, como había defendido Connor en otro trabajo ${ }^{12}$. Son ejemplos claramente definidos de Estados-nación, donde el Estado personifica la idea misma de nación.

Pero la indistinción entre ambos términos, a los que llegan a sumarse en un mismo campo semántico, como ha señalado Connor, los de etnicidad, primordialismo, pluralismo, tribalismo, regionalismo, comunalismo o parroquialismo ${ }^{13}$, no oculta, sin embargo, su diferente configuración política: anterior al Estado en el caso del nacionalismo y posterior a éste en el caso del patriotismo. Asi lo advierte Norbert
Elias al analizar el fenómeno del nacionalismo cuando escribe que «el ethos nacionalista se funda en un sentimiento de solidaridad y de compromiso que no se dirige sencillamente hacia personas determinadas o hacia una única persona en una posición de dominio como tal, sino hacia un colectivo soberano, que construyen los propios individuos interesados con otros miles o millones de individuos, y que se organiza aquí y ahora como Estados 14. Elias pone de relieve el tipo de solidaridad propio del nacionalismo, ligado a la supervivencia misma del grupo étnico, y su génesis: desde un sentimiento de amor propio que se continúa en un sentimiento idealizado de amor hacia la nación. «El amor hacia la propia nación», comenta, «nunca es sólo un amor al hombre o a grupos humanos a los que se llama "ella"; se trata, en cambio, del amor hacia un colectivo, al que puede llamarse "nosotros" $\gg 15$. La imagen que los individuos se forman por su pertenencia a la nación, observa Elias, resulta ser «un componente de su propia imagen".

Ocurre, sin embargo, que no suele ser cualquier imagen, sino aquella formada por contraposición con una imagen impuesta; fruto, por tanto, de una vindicación del derecho a mantener una identidad colectiva nitidamente diferenciada. La representación no constituye estrictamente un retrato sociológico, sino que sc identifica con el ideal del retrato colectivo. $\mathrm{Y}$ aunque la historia juega un papel fundamental como recurso legitimador, la imagen ideal sucle remitir a un pasado mítico o heroico donde, de acuerdo con el relato, se pusieron a prueba de forma definitiva los lazos de solidaridad por los que el grupo étnico, la nación, se hace ya identificable. Como había destacado Max Weber, es en ese pasado primordial cuando la idea de nación se manifiesta bajo la forma de una misión colectiva, que confiere prestigio a sus portadores y los aúna en torno a un destino común inesquiva- 
ble ${ }^{16}$. Pero ya antes, en su lección inaugural en la Universidad de Friburgo, pronunciada en mayo de 1895, “Der Nationalstaat und die Volkswirtschaftspolitik"; pone de manifiesto que el componente del prestigio étnico presente en el nacionalismo va aparejado con la aspiración al poder político. Ése es su rasgo distintivo, que lo diferencia, según Weber, de la etnicidad en sentido estricto. El nacionalismo se define originariamente por su voluntad de autoconstitución política.

En la Alemania de la época era justo la carencia de dicha voluntad lo que invalidaba todo intento de aplicar una política nacional. El Gobierno, en su opinión, no la tenía, pero tampoco estimaba Weber que hubiera alguna alternativa viable en aquel momento. Defiende en la lección que la política económica de Alemania, en tanto que Estado nacional, debía estar guiada por el interés político de la nación y no, en cambio, por el interés político de los grupos económicos, como así ocurría hacia 1895. Advierte asimismo que «poder económico y vocación por la dirección política de la nación no siempre coinciden» ${ }^{17} \mathrm{y}$ que la confluencia de ambos objetivos (en este caso bajo la aristocracia cconómica), habia introducido un serio riesgo para la vida política: «la consecución del poder económico (okonomische Macht) ha sido en todas las épocas la que permite que surja cn una clase su aspiración a la dirección política (politische Leitung). Peligroso e incompatible con los intereses de la nación es cuando una clase política decadente [en referencia a la aristocracia] ticne en su mano la dominación política ( $p o$ litische Herrschaft). Pero más peligroso es cuando las clases que alcanzan poder económico y basan en ello su aspiración al poder político [la nueva burguesía], no se encuentran aún maduras para la dirección del Estado ${ }^{18}$. El riesgo de involución podía evitarse si el equilibrio político se construía no supeditado al equilibrio de los poderes económicos, pero faltaba una voluntad política definida que asumiera la dirección del Estado como el gobierno de una auténtica política nacional (orientada por los intereses de la nación), máxime cuando las migraciones polacas habian cambiado el equilibrio de rentas en los territorios del este.

Para el joven Weber nacionalista, la coexistencia de ambas nacionalidades obligaba a priorizar una estrategia política de consenso nacional en la tarea del gobierno, que tendría que asemejarse, en su opinión, a la política de las nacionalidades aplicada por el gobierno imperial ruso. Una opinión ciertamente discutible y desmentida en la práctica por su resultado final (unanimidad impuesta). Con todo, ésta y otras experiencias políticas a lo largo del siglo han acabado por consolidar la estrategia del consenso (de diseñar la política en función de compromisos) como una estrategia de gobierno imprescindible en cualquier Estado de naturaleza plurinacional. Pero no sólo la búsqueda del consenso ha presidido la historia política del nacionalismo.

La construcción en negativo de la identidad colectiva, casi bajo la forma política schmittiana de amigo/enemigo, ha caracterizado, sin cmbargo, la cvolución de las naciones europeas desde el siglo xvm al siglo xx y el tipo de identidad construida se superpone, cuando no subsume, a la identidad política o constitucional derivada de la pertenencia a un Estado determinado. Al mismo tiempo, el nacionalismo ha perdido su carácter aristocrático original (en un principio sólo las élites aristocráticas adquieren conciencia de su especificidad como pueblo) y se ha ampliado, especialmente desde el siglo $\mathrm{XIx}$, hasta convertirse en un credo omnicomprehensivo, que llega incluso a atribuirse el bagaje simbólico del patriotismo. La interpretación de Weber perfila aún más el telos de la identidad nacionalista al definirla en términos estrictamente políticos. Por esa razón puede criticar la crisis nacionalista de un Estado-nación como Alemania. A 
su juicio, la clase obrera alemana se muestra tan inmadura políticamente como la burguesía: le falta «el clevado instinto de poder de una clase con vocación de liderazgo político» ${ }^{19}$. Esa condición, concluye Weber, de la que participan las clases obreras francesas e inglesas al apoyar a sus respectivos gobiernos en su política de «posición de potencia mundial 20 .

Si la lealtad nacionalista fragua en torno a la idea de pueblo, es decir, en torno a la historia y la cultura de un grupo étnicamente identificado, homogéneo y diferente del resto de los pueblos, la lealtad patriótica se consolida en tomo a un sistema de instituciones que, por principio, ha debido ser construido. El patriotismo, la virtud cívica por excelencia, se genera sobre la base de la adhesión emotiva y racional a un sistema político, que no es interpretado como la creación del genio nacional, sino como producto del acuerdo de la comunidad. En el caso de la lealtad nacionalista, en cambio, los lazos de solidaridad no se crean por participar de un lenguaje común ni tampoco de una comunidad de sangre (rasgos éstos insuficientes para caracterizar al nacionalismo), como ya habia señalado Max Weber ${ }^{21}$. Los lazos se crean, por el contrario, a raíz de la participación en un legado cultural común. En el que se nace y que configura el horizonte histórico para entender el presente.

Pero en esa contribución al imaginario colectivo no todos los individuos ni todos los sectores sociales sienten por igual su lealtad a la nación, dado que lo que pone en jucgo su lcaltad, junto al componente de la dignidad, es su participación real en el poder político. El nacionalismo construye asi una argumentación que ofrece una solución política al rompecabezas de la pluralidad cultural, como había mostrado Gellner en su libro de 1964 Thought and change, pero esa solución, matizada según los casos, pues no toda comunidad cultural puede reivindicar de por sí el derecho a la autodeterminación, llevará a plan- tear la cucstión de la identidad en términos de un desigual acceso al poder.

En fin, quizá sea este último punto el que permita conseguir un mayor contraste con la lealtad patriótica y, sobre todo, con el patriotismo republicano, de raiz cívicoigualitarista. Aun así, conviene recordar que lambién un espíritu igualitario caracteriza de raíz al nacionalismo, pues la conciencia nacional se forma como reconocimiento de la pertenencia a una comunidad etnica. En la pertenencia no cabe elección (se nace miembro de la nación) y, por ende, tampoco cabe distinción. Subroga en principio cualquier diferencia de clase o status, sólo que, y en este punto cobra validez la advertencia de Weber, cuando el nacionalismo se institucionaliza como sistema político la conciencia de igualdad queda diluida en un nuevo marco de relaciones burocratizadas. Ahi, sin embargo, la creación de los Estados nacionales marca una ruptura definitiva con el mundo medieval. El acceso a la vida política, como ha destacado Bendix ${ }^{22}$, no será ya más un privilegio hereditario, sino que dependerá de un sistema de oportunidades educativas y socio-económicas.

Si bien el patriotismo surge con la institucionalización política de toda sociedad libre, y así encontramos ejemplos desde las culturas más antiguas, el nacionalismo, en cambio, es un fenómeno de la modernidad. Su origen puede datarse con la Revolución francesa. Ya en la Declaración de Derechos de 1789 se atribuye la soberanía a la nación y de igual modo en la Constitución de 1791, aunque no así en la de 1793. Pero lo cierto es que desde entonces la nación se convierte en sujeto político central para el constitucionalismo moderno. De significar originariamente, en el mundo romano, una comunidad mayor que la familia pero menor que el pueblo, pues se constituía en virtud del lugar de nacimiento, la nación (natio) pasa a designar durante la Edad Media, en el escenario cosmopolita de las universida- 
des, a las difcrentes comunidades de estudiantes exiranjeros.

A partir de entonces el vínculo de la lengua se asume como rasgo identificador de la nacionalidad e incluso, posteriormente durante el Romanticismo decimonónico, como su rasgo esencial ${ }^{23}$. En la era de las Revoluciones, el siglo xvm, el término «nación» representa al conjunto de los ciudadanos del Estado, el pueblo soberano, y, por extensión, al Estado mismo en tanto que entidad territorial. Justo en el contexto revolucionario los atributos políticos de la nación cobran primacía sobre sus rasgos étnicos y lingüísticos ${ }^{24}$. Será entonces cuando se haga patente la filiación entre nacionalismo y patriotismo, cntre la lealtad a la comunidad nacional y la lealtad a su sistema de instituciones, pues en ese momento el nacionalismo constituye la expresión emancipadora distintiva de la naciente vindicación democrática ${ }^{25}$. Pero no durará mucho esta filiación. A la vuelta de siglo se invertírá el significado universalista del nacionalismo. El nuevo nacionalismo, post-revolucionario y romántico, irá ligado a la vinducación de la estatalidad para cada comunidad étnica.

Volviendo al tema que nos ocupa, el antecedente (que contiene los caracteres básicos de un patriotismo universalista) se encuentra en la República de Roma. Su sistema político constituye una síntesis audaz entre la idea de juridificación de la vida civil y la protección constitucional de las libertades individuales.

"Sicmpre ha sido Roma, la República romana, sobre cuyo radiantc recuerdo se ha iluminado el patriotismo en Europas, escribe Sternberger en su artículo «Das Vaterland", aparecido en 1959 en el Frankfurter Allgemeine Zeitung, que ilustra su interés investigador en el patriotismo, cultivado ya desde la década de los cuarenta ${ }^{26}$. «La patria», continúa el texto, «es la "república", que nos constituye. La patria es la Constitución, que nos da vida.
La patria es la libertad, [la auténtica libertad] de la que gozamos cuando nosotros mismos la defendemos, la usamos y la conservamos» ${ }^{27}$. Veinte años despućs, con motivo del trigésimo aniversario de la Ley Fundamental prepara para el mismo diario su «Verfassungspatriotismus». El acto se vive en Alemania de un modo más reflexivo que festivo. La Constitución, que declara su carácter de provisionalidad en el Preámbulo, se ha convertido en un símbolo de la esperanza de reunificación para el pueblo alemán. Ha provisto asi del marco normativo necesario para instaurar de nuevo la vida civil. Como Sternberger señala, ha contribuido a transformar la vida pública, donde se ha hecho normal que los ciudadanos ejerzan las libertades que la Constitución garantiza. De ese modo, Iento y persuasivo, los ciudadanos se han formado una nucva conciencia colectiva, «un segundo patriotismo, fundado sobre la Constitución». Eśs cierto que kel sentimiento nacional permanece herido: no vivimos en una Alemania plena», rcconoce Sternberger, «pero vivimos en una Constitución plena, en un Estado constitucional pleno, y eso es ya de por sí una forma de patria ${ }^{28}$.

Una forma de patria eminentemente republicana. Y nó al modo de la polis griega, que identificaba comunidad política y comunidad moral. La república, en cambio, se constituye como comunidad de derechos que iguala a sus integrantes por el estatuto jurídico de la ciudadanía y no requiere para la pertenencia ninguna forma de solidaridad, excepto la solidaridad cívica con la república. El patriotismo republicano se traduce en una adhesión a la ley $y$ al sistema político que hacen posible el ejercicio de la libertad civil. Más allá de esa condición, el patriotismo es, $y$ debe ser, compatible con el pluralismo moral. Pero, por supuesto, también con el pluralismo cultural y étnico. Se sitúa, por tanto, y al menos desde Roma, en el plano de la adhesión constitucional y justo por 
esa razón resulta compatible con la cxtensión del pluralismo.

No obstante, la sola lealtad patriótica no consolida, como resulta obvio, una cultura política de la tolerancia. La fomenta, en efecto, al tiempo que la tolerancia opera como condición básica para la formación de la identidad política republicana. Pero también de la identidad nacionalista. Ninguna de ellas, sin embargo, es ajena al riego de radicalización, aunque éste viene ya de algún modo anticipado por el grado de adhesión que cada forma de identidad espera o exige de los individuos. En concreto, por las razones que esgrime para tal fin. La lealtad puede implicar el sacrificio de la propia vida (por la nación o por la patria). En ambos casos se muestra la tensión que Norbert Elias ha descrito en el caso de los nacionalismos de los siglos XIX y xx, formados en el seno de sociedades liberales: un canon moral escindido entre la defensa de la libertad del individuo $y$ la defensa del Estado nacional como valor supremo ${ }^{29}$. Para el nacionalismo, la tensión se resuelve críticamente salvando a la comunidad, pues ésta es la condición última, o primera, para la libertad. Para el republicanismo las razones de la libertad cobran prioridad vital sobre las razones de la comunidad, pues el sentido ultimo de la república se cifra en la salvaguarda de la libertad del ciudadano.

\section{Patriotismo constitucional}

Subyace a la lectura de Sternberger una interpretación muy definida del significado de los términos «estado», "pueblo»y «constitución». Su contenido semántico incorpora el cambio institucional desde el primer Estado liberal hacia el Estado democrático constitucional y una de sus consecuencias: la necesidad de orientar hacia ese mismo fin la reforma del Estado nacional. Ciertamente, la historia del Estado-nación es la historia misma del Estado moderno y de sus transformaciones desde el siglo xvill. Pero en ese proceso, asincrónico entre los Estados europeos, Alemania presenta diferencias específicas, sobre todo a partir de la segunda mitad del siglo $\mathrm{xIx}$, cuando por el influjo del romanticismo en la politica se asume constitucional y politicamente la asimilación de la idea de pueblo con el modelo de Estado. También es cierto que la historia de la unidad alemana ha sido efímera en sentido estricto. Al respecto, Habermas recuerda que sólo durante los 75 años del Reich de Bismarck cabría hablar de dicha unidad, pues incluso hasta $1938^{30}$ el Reich y Austria mantenían una existencia «paralela». No obstante, la idea de dicha unidad no ha desaparecido y pervive hoy día en el imaginario político de los alemanes (si es que puede hablarse en unos términos tan genéricos).

Desde esa perspectiva, el pueblo, entendido como comunidad fraternal (creada por vínculos de sangre) y como comunidad de cultura identificada por un destino común (Schicksalsgemeinschaft), encuentra su cumplimiento en la realización del Estado. La relación entre pueblo y Estado está tramada, pues, como un relato, cuyos elementos históricos han entrado a formar parte de una historia mitificada (en el sentido de sustrato narrativo del que se nutre la imaginación política nacionalista). La Constitución viene a codificar en parte el material mítico-histórico del relato, que pasa así a recibir una impronta normativa: pues desde la constitución se interpretará ya el sistema de instituciones y la vida pública de la sociedad. Desde la perspectiva del Estado constitucional, en cambio, el pueblo aparece descrito como el conjunto de la ciudadanía, cuyo vínculo de unión no es natural, sino de carácter político. El Estado tiene un origen contractual, como también lo tiene la constitución, que orienta, a su vez, en tanto que marco normativo, toda la construcción del edificio de instituciones del Estado. 
Pero no son dos perspectivas incomunicadas entre sí. En realidad, nacionalismo y constitucionalismo (republicano) experimentan una fusión inicial con la Rcvolución francesa, cuando el término "nación» se convierte uen un rasgo constitutivo de la identidad política de los ciudadanos de una comunidad democrática» ${ }^{31}$. Desde entonces se encuentran ya disponibles las condiciones que permiten una evolución conjunta, aunque diferenciada por el distinto peso que cada uno de los componentes pueda asumir. La lectura de Sternberger, y posteriormente la de Habermas, pone en cuestión la viabilidad democrática de la vía nacionalista por sí sola: la evolución hacia el republicanismo constituye la única alternativa democrática, pero ésta debe incorporar el componente nacionalista. E] patriotismo constitucional representa una alternativa razonable de identidad política: supranacional y al mismo tiempo compatible con un pluralismo de identidades nacionales, como defenderá Habermas, en una línea similar a la idea del «overlapping consensus» de Rawls.

La República de Weimar, entre los años 1919 y 1933, supuso un contrapeso de la tradición nacionalista, asi como de la tradición imperial, pero su crisis y el fracaso final del proyecto republicano propició una recuperación de la política nacionalista-romántica. En la más desquiciante de sus versiones, que mostró la inviabilidad de un equilibrio ensayado hasta entonces entre republicanismo y nacionalismo. A su término, la Ley Fundamental de 1949 inaugura un período de reconstrucción democrática. Una apuesta decisiva del pueblo alemán por integrar los principios del Estado constitucional en la vida política, como recuerda Sternberger. El proyecto exige abandonar el objetivo de una democratización radical del tejido sociopolítico, como pretendía la Constitución de 1919, pero a cambio sus resultados han proporcionado la estabilidad política y la garantía de una democratización si no radical, al menos sî continua. Ahora se ha podido ver que la vida de la Constitución depende de la salud de la vida civil y que ésta encuentra cn la Constitución un marco jurídico cstable para la conviviencia.

En 1982, con motivo del XXV aniversario de la Academia para la Formación Política, Sternberger pronuncia un discur$\mathrm{so}$, de nuevo con el título de aVerfassungspatriotismus", que aparecería publicado en el Frankfurter Allgemeine Zeitung del 31 de agosto, donde retoma y amplía considerablemente las ideas de su artículo anterior. Comienza por admitir que con la idea de patriotismo constitucional ha tratado de realizar una aportación pedagógica. En realidad, la ha propuesto como una «clave para la formación política». No otro es el significado del patriotismo en la tradición republicana, de la que se reconoce una vez más partícipe.

Ante la pregunta por el significado del patriotismo, señala Stemberger que la mayoría tiende a asociarlo «con el patriotismo de la nación, el patriotismo nacional, mientras que, por cl contrario, apenas o nunca con el modelo de Estado en que viven ni con su constitución». Sin embargo, uen sus orígenes y en su historia, en su historia moderna, tiene que ver con el Estado y con la Constitución' ${ }^{32}$. Y éste es el argumento más dificil de mostrar, pues aunque el patriotismo sea anterior al nacionalismo y, por supuesto, al Estado moderno, es en la modernidad cuando se produce la articulación entre las tres instancias (Estado, Constitución y patriotismo). En Alemania el debate constitucionalista se desencadena, al igual que en el resto de Europa, en la segunda mitad del siglo xvil.

Un precedente fechado en 1761, que Sternberger cita, así lo atestigua. Pcrtenece al autor alemán Thomas Abbt y lleva por título "Vom Tode fürs Vaterland" (De la muerte por la patria). Su primera frase refleja ya el ideal republicano: «La voz de la patria no puede escucharse cuando se 
ha sofocado el viento de la libertad ${ }^{3}{ }^{3}$. Un segundo fragmento lo ilustra con mayor detalle: aCuando el nacimiento o mi decisión libre me unen con un Estado, a cuyas benéficas leyes me someto, leyes que ya no me privan de mi libertad, como así es necesario para el bienestar de todo el Estado, llamo entonces a ese Estado mi patria» ${ }^{34}$. Stemberger hace notar que al presentar la idea de patriotismo el autor apenas habla de pueblo o de tierra, sino ude las leyes del Estado y de la libertad de la personam, y que son estos elementos los que permiten considerarlo ya «un concepto político-constitucional de patrias ${ }^{35}$. Que no llego a jugar un papel destacado en la historia politica posterior, aunque sí tuvo una cierta relevancia.

Desde el siglo xix, sin embargo, la autoconciencia política de los alcmanes ha tendido a reconstruir el pasado bajo la imagen de una única tradición de síntesis, cuando la realidad ha sido la de una historia con fisuras que no siempre ha recuperado la unidad. Se ha tratado, más bien, de toda una serie heterogénea de tradiciones donde converge, en efecto, la tradición republicana. Por csa razón, conviene considerar toda una pluralidad de factores a la hora de reconstruir los contornos de la identidad colectiva, y entender que esa misma identidad se define históricamente. Por eso mismo, el método de trabajo no permite historificar en un mismo nivel de comprensión todos sus momentos, puesto que no forman una historia única o lineal, sino que exige justificar la comprensión histórica de cada momento. La no distínción de esta diferencia llegó al paroxismo durante el Tercer Reich, tras una clara pero perversa identificación del patriotismo con la lealtad al régimen: cuando paradójicamente los fundamentos universalistas del patriotismo (la libertad y el derecho justo) habían sido negados. Sin embargo, esa apropiación del ethos patriótico bajo Hitler dejaría una huella profunda. Tanto que aún no deja de producir cierta inquietud, como observa Sternberger, reconocer el sentimiento patriótico $y$, más incluso, manifestarlo en público. Será un signo de salud cívica poder hacerlo y, con ello, diferenciar de otras formas de lealtad colectiva al patriotismo fundado en el derecho y la libertad.

Sobre este último deseo político versa también en parte una de sus últimas intervenciones públicas, en un coloquio sobre el patriotismo celebrado por su octagésimo cumpleaños en la Universidad de Heidclberg, el 6 de noviembre de $1987^{36}$. Su alocución repasa muy brevemente algunos hitos de la historia del patriotismo, desde Cicerón hasta el humanismo cívico del Renacimiento italiano, para destacar con énfasis el papel critico que la memoria histórica debe jugar al reconstruir con todos sus cla roscuros los antecedentes de la identidad colectiva. Una memoria histórica formada en tiempos de libertad no puede permitirse un acercamiento distorsionante al pasado. Sin esa condición, el patriotismo se habrá educado sobre la experiencia de una conciencia histónica mitificada, recuperando en fin las palabras de Habermas, que ponen ahora de relieve su profunda afinidad con las de Sternberger. 


\section{NOTAS}

I Recogido en Eine Art Schadensabwicking. Kleine politische Schriften V, Suhrkamp, Frankfurt am Main, 1987, p. 168 .

2 "Grenzen des Neohistorismus", en Die nacholende Revolution. Kleine politische Schriften VII, Suhrkamp, Frankfurt am Main, 1990, p, 150.

3 Thid, p. 152.

4 ibial. pp, 205 y ss.

"Fakizität und Goltung, Suhrkamp, Frankfurt am Main, 1992, pp. 632 yss.

* Recogida, con modificaciones, en Die Einbeziehung des Anderen, Suhrkamp, Frankfurt am Main, 1996, pp. $128-153$.

7 "Beyond reason: the nature of the ethnonational bond*, Ethnic and Racial Studies, núm. 16, 1993, p. 374.

* A nation is a nation, is a state, is an ethnic group, is a...", Ethnic and Racial Studies, num. 1, 1978, pp. 379 yss.

7 rbid.

16 "Ein Exkurs übor Nationalismus», Studien über die Deutschen, Suhrkamp, Frankfurt am Main, 1989, p. 196.

11 Ibid., pp. 196-197.

12 Gesammelte Aufsätze zur Soziologte utt Soziat politi, 2, ed., Tubingen, J. C. B. Mohr, 1988, pp. 484 Y 5 s.

1. «Der Nationalstat und die Volkswirtschaftspolitikn, en Gesanmelte politische Schriften, 4." ed., Tübingen, J. C. B. Mohr, 1980, p. 18.

14 Ibid., p. 19.

15 Ibid, p. 22 is Ibid, p. 23.

17 Witschaft und Gesellschaft, $5 . * \mathrm{~cd}$, J. Winckelmann (ed.), Tübingen, J. C. B. Mohr, 1972, II. viii. $\$ 5$, pp. $527-530$.

Nation-bulding and citizenship: studies of our changing social order, nueva ed. ampliada, Berkeley, University of California Press, 1977, pp. 127-128.

19 Elie Kedourie, Nationatism, 4. ${ }^{3}$ ed. ampliada, Oxford, Blackwell, 1993, pp. 5 y ss.

7 Eric J. Hobsbawm, Nations and nationalism since 1780: programme, myh, reality, $2{ }^{a} \mathrm{~cd}$. Cambridge, Cambridge University Press, 1992, pp. 14 y ss.

21 Leah Greenfeld, Nationalism: five roads to modernity, Cambridge, MA/London, Harvard University Press, 1992, pp. 10 y ss.; Schwarzmantel, «Nacionalismo y democracias, Revista Internacional de Filosofia Politica, Júm. 3, 1994, pp. 18-25.

22 En Dolf Sternberger, Schrifien, vol. X, Insel, Frankfurt am Main, 1990, p. 11.

2. Ibid., p. 12 .

${ }_{24}$ Ibid, p. 13.

2s «Ein Exkurs über Nationalismus», loc. cit, pp. $208-210$.

3* stenzen des Neohistorismus, loc. cis., p. 151.

27 Jürgen Habermas, Faktizitât tund Geltung, p. 636.

${ }_{21}$ Dolf Sternberger, Schiffen, p. 20.

${ }^{29}$ Ibid, p. 21.

30 Ibid., p. 22.

3 Ibid.

32 Ibid., pp. 32-37. 